\title{
HOMOLOGACION DE PRODUCTOS INDUSTRIALES Y DE EQUIPOS DE SEGURIDAD EN EL TRABAJO
}

\author{
POR \\ ISABEL BENZO SAINZ
}

\section{9) Concepto}

La homologación es un acto concreto que se inserta dentro del proceso dirigido a garantizar la calidad y seguridad de determinados productos. En dicho ámbito, la homologación puede definirse como el acto de naturaleza ejecutiva, que tiene por objeto la comprobación $y$ declaración oficial de que un producto cumple con los requisitos $y$ especificaciones técnicas que le sean de aplicación.

Para los productos sometidos preceptivamente a homologación, ésta constituye requisito necesario para la puesta en el mercado y la libre circulación de los mismos por el territorio nacional, así como para su exportación.

\section{$\left.2^{9}\right)$ Delimitación de competencias}

El título competencial aplicable en materia de homologación está en función de la naturaleza de los productos sobre los que la misma recae, por lo que, si bien en la mayoría de los casos la homologación afecta a productos industriales y en consecuencia se aplica el título relativo a industria, también pueden ser de aplicación otros títulos como el de trabajo o sanidad.

Partiendo de lo anterior y de la consideración de la homologación como un acto de naturaleza ejecutiva, cabe afirmar que corresponderá el ejercicio de las facultades de homologación al ente que sea titular de competencias ejecutivas en el ámbito material respectivo.

De acuerdo con lo dicho, las Comunidades Autónomas que sean titulares de competencias ejecutivas en el ámbito material respectivo (ya sea industria, trabajo o sanidad) serán competentes para homologar los productos fabricados en su territorio, cuya homologación se solicite de los órganos autonómicos, y siempre que ésta se realice de conformidad con las normas y reglamentaciones técnicas que resulten de aplicación al producto.

El reconocimiento de las citadas competencias autonómicas plantea diversos problemas concretos, todavía no definitivamente resuel- 
tos, y que han dado lugar a una abundante conflictividad que ha llegado hasta el Tribunal Constitucional.

La base o la razón fundamental de esta conflictividad radica en torno a una cuestión específica : el ejercicio de las facultades autonómicas de homologación va a permitir la puesta en el mercado del producto y su libre circulación por todo el territorio nacional, asi, como su exportación. Esta afirmación exige partir de una premisa previa: en materia de homologación, el principio general de limitación territorial de las competencias autonómicas juega en cuanto al lugar de fabricación del producto pero no en cuanto a sus posibilidades de circulación posterior;ello resulta obvio, puesto que limitar los efectos de la homologación autonómica al territorio de la Comunidad Autónoma equivaldría en la práctica a la negación o vaciamiento de las facultades autonómicas en este ámbito y seria tan absurdo como negar a las Comunidades Autónomas la competencia para realizar la inspección técnica de un vehículo por el hecho de que éste vaya a circular por todo el territorio nacional. Como ya ha señalado en diversas ocasiones el Tribunal Constitucional, no puede negarse a las Comunidades Autónomas el ejercicio de las competencias que les corresponden por el hecho de que sus actos sean susceptibles de producir efectos más allá de sus límites territoriales.

Partiendo pues de ese alcance supraterritorial de las competencias autonómicas en materia de homologación, se han planteado una serie de problemas diversos, entre otros: a) la necesidad de que el Estado disponga de mecanismos internos suficientes para hacer frente a su responsabilidad internacional en relación con las homologaciones autonómicas; b) la necesidad o no de un reconocimiento expreso por el Estado o por las restantes Comunidades Autónomas de las homologaciones efectuadas por una de ellas: c) la determinación del ente competente para homologar un producto cuyos componentes han sido fabricados en distintas Comunidades Autónomas ; etc.

Se trata, como señalábamos antes, de problemas aún no resueltos y que exigen necesariamente el establecimiento de mecanismos de coordinación a nivel estatal; pero, en cualquier caso, se trata de cuestiones que habrán de ser examinadas en el seno del nuevo marco que introduce el sistema comunitario, que tiende a sustituir las homologaciones administrativas por homologaciones realizadas por organismos de carácter privado, lo que hace que muchos de estos problemas adquieran un nuevo enfoque.

Al margen de estos problemas, queda una última cuestión por resolver en lo que se refiere a la delimitación de competencias entre el Estado y las Comunidades Autónomas en materia de homologación , y es la relativa a la determinación del ente competente para homologar los productos procedentes del exterior. 
En el momento presente, y sin perjuicio de lo que más adelante se señalará, el Estado ha venido afirmando su exclusiva competencia para homologar los productos importados, por estimar que la citada facultad forma parte de sus competencias exclusivas en materia de comercio exterior (art. 149.1.10 de la Constitución).

La utilización del mencionado título competencial deriva directamente del hecho de que la homologación de los productos importados se ha utilizado tradicionalmente en todos los paises como un obstáculo o barrera técnico-comercial al servicio de los intereses nacionales, adelantando o retrasando la homologación de estos productos según convenga a los intereses de la producción nacional.

\section{3) El sistema comunitario: el mercado único europeo y el lla- mado "nuevo enfoque" de las Directivas comunitarias en materia de homologación}

El establecimiento de un mercado único europeo y su corolario de libre circulación de personas, productos y capitales, va a producir importantes repercusiones en relación con el tema que nos ocupa. Así, principalmente, el hecho de que la homologación de un producto, realizada en cualquiera de los Estados miembros produce automáticamente efectos en la totalidad del territorio comunitario, esto es, va a permitir la puesta en el mercado y la libre circulación del producto por todo el territorio de la Comunidad Europea, puesto que el sistema se basa en el reconocimiento mutuo por todos los Estados miembros de las homologaciones nacionales. Ello implica a nivel interno, entre otras, las siguientes consecuencias:

a) La desaparición de la posibilidad de una homologación nacional de los productos procedentes y ya homologados por alguno de los paises miembros de la CEE, pues tales productos gozan de libre circulación por todo el territorio nacional, sin necesidad de nuevos controles (salvo que se estimase que la homologación no había sido debidamente realizada, en cuyo caso procedería acudir a los procedimientos de denuncia previos por el propio derecho comunitario).

Desaparece, por tanto, la homologación estatal de los productos importados de paises miembros de la CEE, $y$, en consecuencia, la posibilidad de utilizar el título de "comercio exterior" como fundamento de esa competencia homologadora estatal, pues una de las consecuencias del mercado único es precisamente la desaparición de las barreras comerciales. Dicho título sólo podrá ser utilizado respecto a productos importados de paises no miembros de la CEE. 
b) La homologación realizada en España produce efectos en la totalidad del territorio comunitario. Ello implica que, si se acepta la tesis antes expuesta respecto de las competencias autonómicas en este ámbito, la homologación autonómica (ya sea realizada directamente por los organismos oficiales o por entidades privadas acreditadas por la propia Comunidad Autónoma) produciria automáticamente efectos en cuanto a la libre circulación del producto por todo el territorio comunitario.

Ello plantea nuevamente la cuestión que ya antes apuntábamos, eso es, la necesidad de arbitrar a nivel interno los mecanismos adecuados para garantizar la responsabilidad internacional del Estado puesto que, como es sabido, el Estado es el único responsable ante la Comunidad de las homologaciones nacionales.

Los mecanismos aplicables a este respecto habrán de ser objeto de un estudio y examen pormenorizados, por lo que únicamente cabe apuntar algunas ideas: por un lado, deberán asegurar plenamente la garantía de las homologaciones autonómicas, al mismo nivel que las realizadas por el Estado; $y$, por otro, habrán de basarse en técnicas de coordinación entre el Estado y las Comunidades Autónomas, y no de sustitución por el Estado de las facultades autonómicas.

c) Una última cuestión, que se conecta con la anterior, deriva del hecho de que en un sistema de mercado único y libre circulación no parece que pueda negarse la posibilidad de que los productos puedan ser homologados en cualquier parte del territorio comunitario, es decir, se reconozca al empresario o fabricante la facultad de decidir libremente el lugar en que desee solicitar la homologación del producto, de forma que, por ejemplo, un empresario belga pueda homologar su producto en Cataluña o un industrial vasco hacerlo en Holanda.

Ello hace que pueda ponerse en duda la afirmación antes realizada de que la competencia autonómica de homologación se limita a los productos fabricados en su territorio, y, paralelamente, obliga a un replanteamiento global del sistema a nivel interno, puesto que las homologaciones autonómicas tienen no ya un alcance supra-autonómico sino supranacional, lo que de nuevo plantea el tema de los mecanismos de coordinación que hagan posible un reconocimiento estatal de las mismas. Junto con las consecuencias derivadas del mercado único europeo, es preciso analizar también lo que se ha denominado el "nuevo enfoque" del derecho comunitario en materia de homologación, que ha tenido su reflejo fundamentalmente en las 
Directivas $88 / 378$ de seguridad de los juguete y $89 / 686$ sobre equipos de protección individual. El nuevo sistema se asienta en los siguientes postulados:

19) La definición, a nivel comunitario, de las características técnicas de los productos $y$ de las exigencias esenciales de seguridad y calidad que deben reunir los mismos para poder beneficiarse de la libre circulación en la Comunidad, así como de los procedimientos de control aplicables para comprobar el cumplimiento de las mencionadas exigencias. Se encomienda a los Estados miembros la labor de transposición de las Directivas en las que se define el nuevo sistema. La primera cuestión que se plantea, a nivel interno, es pues la de determinar el ente competente para el ejercicio de las potestades legislativas de transposición de las Directivas comunitarias. En principio, y atendiendo a las materias sobre las que recae la regulación comunitaria (fundamentalmente industria y trabajo) cabría afirmar que corresponde al Estado el ejercicio de las citadas facultades legislativas, pues en ambos casos se trata de materias en las Comunidades Autónomas carecen de potestades normativas plenas, habiendo asumido, en todo caso, bien competencias de ejecución de la legislación estatal (en materia de trabajo) bien competencias exclusivas sin perjuicio de lo señalado en las normas estatales (en materia de seguridad industrial). Por ello, cabe estimar, no sin una importante matización -pues bastaría recordar las competencias exclusivas del País Vasco en materia de industria- que, con carácter general es competencia del Estado la transposición de las Directivas comunitarias en las que se recoge el "nuevo enfoque" en materia de homologación.

29) La sustitución del sistema tradicional de homologación administrativa por un procedimiento de certificación realizado por entidades $u$ organismos de naturaleza privada.

La normativa comunitaria distingue fundamentalmente dos tipos de entidades: los laboratorios de Ensayo encargados de la realización de los informes y protocolos de ensayo que servirán posteriormente para emitir el certificado "CE" de tipo; y los Organismos de Certificación propiamente dichos a los que se encomienda la emisión del certificado "CE", que equivale a la homologación de tipo, y la aprobación de los modelos autorizados.

Las Directivas comunitarias encomiendan a los Estados la competencia para la autorización o acreditación de estos Organismos, que deberá hacerse de conformidad con lo 
dispuesto en las legislaciones nacionales que traspongan las normas europeas, y la competencia para notificar o comunicar dicha autorización a los órganos comunitarios.

En cuanto a las consecuencias que a nivel interno se derivan de la aplicación del nuevo sistema comunitario, cabe destacar ante todo, y conectando con lo anteriormente señalado, que corresponde al Estado en uso de sus facultades legislativas en esta materia, la competencia para determinar normativamente los requisitos y condiciones que han de cumplir los mencionados organismos, así como el procedimiento que haya de seguirse para la autorización de los mismos.

Pero, además del ejercicio de las potestades normativas en este ámbito, queda por resolver otra cuestión concreta: la competencia para la autorización o acreditación especifica de los Organismos de Certificación nacionales.

Si consideramos que las normas comunitarias no precisan ni ponen límites en cuanto al número de Organismos de este tipo que puedan ser autorizados en cada país miembro, y si tenemos en cuenta que el acto concreto de acreditación o autorización tiene la naturaleza de acto de ejecución, puesto que, al igual que ocurria con la homologación, se limita a comprobar y declarar oficialmente que el Organismo se ajusta a lo dispuesto en las normas que le sean de aplicación, no cabe sino reconocer la competencia de las Comunidades Autónomas para la acreditación de aquellos Organismos situados en sus territorio.

Las cuestiones antes planteadas en relación con las homologaciones autonómicas se reproducen ahora en el ámbito de la autorización de los Organismos de certificación y llevan de nuevo a insistir en lo que constituye la necesidad principal del sistema, esto es, el establecimiento de instrumentos de coordinación adecuados entre el Estado y las Comunidades Autónomas a fin de garantizar la actuación de los Organismos acreditados en España y la responsabilidad que al Estado incumbe respecto de las certificaciones por ellos emitidas.

\section{4) Aproximación de la normativa española al "nuevo enfo- que"comunitario}

a) El Real Decreto 1614/85, de 1 de Agosto, sobre ordenación de las actividades de normalización y certificación, vino a definir, 
junto a la homologación, la actividad de certificación, considerando que es "la actividad consistente en la emisión de documentos que atestigüen que un producto o servicio se ajusta a normas técnicas determinadas".

El art. 5 del Real Decreto preveía que pudiera encomendarse la realización de las actividades de certificación a entidades o asociaciones privadas, y en base a este precepto se creó $A E-$ NOR, como Asociación de normalización y certificación, que emite la marca $\mathrm{N}$ de AENOR.

b) El Real Decreto 800/87, de 15 de Mayo, por el que se establece la certificación de conformidad a normas como alternativa de la homologación de tipos de productos, vino a señalar que el Ministerio de Industria y Energía podrá disponer, para los productos sujetos a preceptiva homologación, que los certificados o marcas de conformidad emitidos por una Entidad autorizada tengan la misma validez que las homologaciones administrativas.

c) Finalmente, cabe señalar que la Directiva $88 / 378$, sobre seguridad de los juguetes ha sido objeto recientemente de transposición por el Estado, a través del Real Decreto 880/1990, de 29 de Junio, por el que se aprueban las normas de seguridad de los juguetes. 
